\title{
F-Prostaglandin receptor regulates endothelial cell function via fibroblast growth factor-2
}

\author{
Margaret C Keightley, Pamela Brown, Henry N Jabbour*, Kurt J Sales
}

\begin{abstract}
Background: Prostaglandin $(\mathrm{PG}) \mathrm{F}_{2 \alpha}$ is a key regulator of endometrial function and exerts its biological action after coupling with its heptahelical G protein-coupled receptor (FP receptor). In endometrial adenocarcinoma the FP receptor expression is elevated. We have shown previously that $\mathrm{PGF}_{2 \alpha}-\mathrm{FP}$ receptor signalling in endometrial adenocarcinoma cells can upregulate several angiogenic factors including fibroblast growth factor-2 (FGF2). In the present study, we investigated the paracrine effect of conditioned medium produced via $\mathrm{PGF}_{2 \alpha}$-FP receptor signalling in endometrial adenocarcinoma cells stably expressing the FP receptor (Ishikawa FPS cells), on endothelial cell function.

Results: Conditioned medium (CM) was collected from FPS cells after 24 hrs treatment with either vehicle (V CM) or $100 \mathrm{nM} \mathrm{PGF} 2 \alpha$ (P CM). Treatment of human umbilical vein endothelial cells (HUVECs) with P CM significantly enhanced endothelial cell differentiation (network formation) and proliferation. Using chemical inhibitors of intracellular signalling, we found that P CM-stimulated endothelial cell network formation was mediated by secretion of endothelial PGF $2 \alpha$ and activation of endothelial FP receptors, following FGF2-FGFR1 signalling, phosphorylation of ERK1/2 and induction of COX-2. Whereas, P CM stimulation of endothelial cell proliferation occurred independently of $\mathrm{PGF}_{2 \alpha}$ secretion via an FGF2-FGFR1-ERK1/2 dependent mechanism involving activation of the mTOR pathway.

Conclusions: Taken together, we have shown a novel mechanism whereby epithelial prostaglandin $\mathrm{F}_{2 \alpha}-\mathrm{FP}$ signalling regulates endothelial cell network formation and proliferation. In addition we provide novel in vitro evidence to suggest that prostaglandin $F_{2 \alpha}$ can directly regulate endothelial cell network formation but not endothelial cell proliferation. These findings have relevance for pathologies where the FP receptor is aberrantly expressed, such as endometrial adenocarcinoma, and provide in vitro evidence to suggest that targeting the FP receptor could provide an anti-angiogenic approach to reducing tumour vasculature and growth.
\end{abstract}

\section{Background}

Endometrial adenocarcinoma, originating from the glandular epithelial cells of the uterine endometrial lining, is one of the most prevalent cancers amongst women in the Western world [1,2]. It is a disease which particularly occurs in post menopausal women and recent evidence suggests that mutations in oncogene expression may play a role in the etiology of the disease [3]. Data generated in our laboratory and others have ascertained a role for the cyclooxygenase (COX)-prostaglandin (PG) axis in the regulation of endometrial adenocarcinomas by increasing cell proliferation and the

\footnotetext{
* Correspondence: H.Jabbour@hrsu.mrc.ac.uk

MRC Human Reproductive Sciences Unit, The Queen's Medical Research Institute, 47 Little France Crescent, Edinburgh, EH16 4TJ, UK
}

secretion of angiogenic growth factors [4,5]. This is similar to other cancers where over-expression of COX enzymes and biosynthesis of prostaglandins has been shown to promote cellular proliferation [6], inhibit apoptosis [7] and enhance angiogenesis [8]. However, the molecular mechanisms mediating the role of prostaglandins in regulating vascular function and angiogenesis are still poorly defined.

Angiogenesis is the process of endothelial cell sprouting from an existing vasculature towards cancer cells [9] and is required by any tumour larger than $2 \mathrm{~mm}$ in diameter [10]. The proposed mechanism of angiogenesis suggests that tumour cells secrete stimulatory factors which act in a paracrine manner on surrounding blood vessels, immune cells and fibroblasts to promote the
Ciomed Central

C 2010 Keightley et al; licensee BioMed Central Ltd. This is an Open Access article distributed under the terms of the Creative Commons Attribution License (http://creativecommons.org/licenses/by/2.0), which permits unrestricted use, distribution, and reproduction in any medium, provided the original work is properly cited. 
proliferation, differentiation and migration of endothelial cells towards the stimulus $[10,11]$. These tumour stimulatory factors include vascular endothelial growth factor (VEGF-A) and fibroblast growth factor 2 (FGF2). In human endometrial adenocarcinomas VEGF-A and FGF2 expression and secretion are elevated [12-14] and both VEGF-A and FGF2 can stimulate angiogenesis in xenografts in vivo $[15,16]$.

In a previous study we demonstrated elevated expression of the FP receptor, FGF2 and the FGF2 receptor 1 (FGFR1) in neoplastic endometrial epithelial and vascular cells and ascertained a role for the FGF2, produced by $\mathrm{PGF}_{2 \alpha}-\mathrm{FP}$ receptor signalling, on epithelial cell proliferation [12]. In this study we have shown that conditioned medium from $\mathrm{PGF}_{2 \alpha}$ treated Ishikawa cells stably expressing the FP receptor (Ishikawa FPS cells), can increase endothelial cell differentiation (network formation) and proliferation. Treatment of Ishikawa FPS cells with $\mathrm{PGF}_{2 \alpha}$ increases FGF2 secretion which in turn activates FGFR1 signalling in endothelial cells and induces the phosphorylation of extracellular signal-regulated kinase (ERK1/2), COX-2 expression and secretion of $\mathrm{PGF}_{2 \alpha}$. Following its release from endothelial cells, we show for the first time that, $\mathrm{PGF}_{2 \alpha}$ promotes endothelial cell network formation in an autocrine/paracrine manner, via the endothelial FP receptor. By contrast, PGF $_{2 \alpha}$ is not involved in endothelial cell proliferation which we show to be regulated by FGF2-FGFR1 signalling via the mammalian target of rapamycin (mTOR) pathway. Taken together, our data highlight two molecular pathways by which $\mathrm{PGF}_{2 \alpha}-\mathrm{FP}$ receptor signalling can regulate endothelial cell function in endometrial adenocarcinomas.

\section{Results}

$\mathrm{PGF}_{2 \alpha}$-FP signalling mediates endothelial cell network formation and proliferation via FGF2-FGFR1 signalling We previously demonstrated elevated expression of the FP receptor, FGF2 and FGFR1 in endometrial adenocarcinoma [12]. Using a neoplastic epithelial cell line stably expressing the FP receptor to the levels observed in endometrial adenocarcinoma (Ishikawa FPS cells), we ascertained a role for FGF2, produced by $\mathrm{PGF}_{2 \alpha}-\mathrm{FP}$ receptor signalling, on epithelial cell proliferation [12]. In addition, we found that FP receptor, FGF2 and FGFR1 co-localised within the vascular endothelial cells in endometrial adenocarcinomas suggesting that $\mathrm{PGF}_{2 \alpha}$ may directly and indirectly regulate endothelial cell function [12]. To determine if the effects of $\mathrm{PGF}_{2 \alpha}-\mathrm{FP}$ receptor interaction in endometrial adenocarcinoma cells on endothelial cell function were mediated by FGF2, we used conditioned medium (CM) from Ishikawa FPS cells treated with vehicle or $100 \mathrm{nM} \mathrm{PGF}_{2 \alpha}$ for 24 hours. The presence of FGF2 in CM from vehicle
(V CM) and $\mathrm{PGF}_{2 \alpha}$-treated (P CM) Ishikawa FPS cells was confirmed by ELISA. Immunoneutralisation of $\mathrm{P}$ CM with FGF2 antibody significantly reduced FGF2 concentration in P CM [12].

To assess the effects of the CM on differentiation (network formation) and proliferation, assays were performed using HUVECs as a model system. Treatment of HUVECs with P CM significantly increased endothelial cell network formation (Fig. $1 \mathrm{~A}$ and $1 \mathrm{~B}, \mathrm{P}<0.05$ ) and proliferation (Fig. $1 \mathrm{C}, \mathrm{P}<0.05$ ) compared to $\mathrm{V} C \mathrm{CM}-$ treated cells. Treatment of HUVECs with P CM in the presence of the FGF2 receptor 1 (FGFR1) tyrosine kinase inhibitor (SU4984) or FGF2-immunoneutralised CM (FGF2-Ab), significantly reduced endothelial cell network formation (Fig. 1A and $1 \mathrm{~B}$; $\mathrm{P}<0.05$ ) and cellular proliferation (Fig. $1 \mathrm{C} ; \mathrm{P}<0.05$ ), confirming that these alterations in endothelial cell function were mediated by FGF2 in the P CM signalling through endothelial FGFR1.

Next we investigated the signal transduction pathways mediating the role of FGF2 in the P CM on network formation and proliferation. HUVECs were treated with P CM in the presence of cell signalling inhibitors of extracellular signal-regulated kinase (ERK1/2; PD98059), mammalian target of rapamycin (mTOR; rapamycin) or phosphoinositide-3-kinase (PI3K; wortmannin or LY294002). We found that the P CM-induced network formation was significantly inhibited by PD98059 but not rapamycin, wortmannin or LY294002 (Fig. 2A, P < $0.05)$. However, endothelial cell proliferation was inhibited by PD98059 and rapamycin but not wortmannin or LY294002 (Fig. 2B, P $<0.05$ ).

We confirmed that endothelial cell proliferation but not network formation was mediated by FGF2-mTOR signalling using recombinant FGF2 protein. Treatment of HUVECs with recombinant FGF2 significantly increased network formation (Fig. 2C; $\mathrm{P}<0.05$ ) and proliferation (Fig. 2D; $\mathrm{P}<0.05$ ). Co-treatment of cells with recombinant FGF2 protein and rapamycin had no effect on network formation, compared to recombinant FGF2 peptide alone (Fig. $2 \mathrm{C} ; \mathrm{P}<0.05$ ). In contrast, rapamycin treatment significantly inhibited endothelial cell proliferation induced by the recombinant FGF2 protein (Fig. 2D; $\mathrm{P}<0.05$ ) confirming that endothelial cell proliferation was mediated by $\mathrm{P} C \mathrm{CM}$ via the FGFFGFR1-mediated induction of the mTOR pathway.

ERK1/2 phosphorylation is regulated by FGF2- FGFR1 signalling

As ERK1/2 was involved in regulating both $\mathrm{P}$ CM induced endothelial cell network formation and proliferation, we investigated the effect of P CM on ERK1/2 phosphorylation. HUVECs were treated with V CM or $\mathrm{P}$ CM for 0, 5, 10, 15, 20 and 30 mins (Fig. 3A). Treatment of HUVECs with P CM significantly increased 


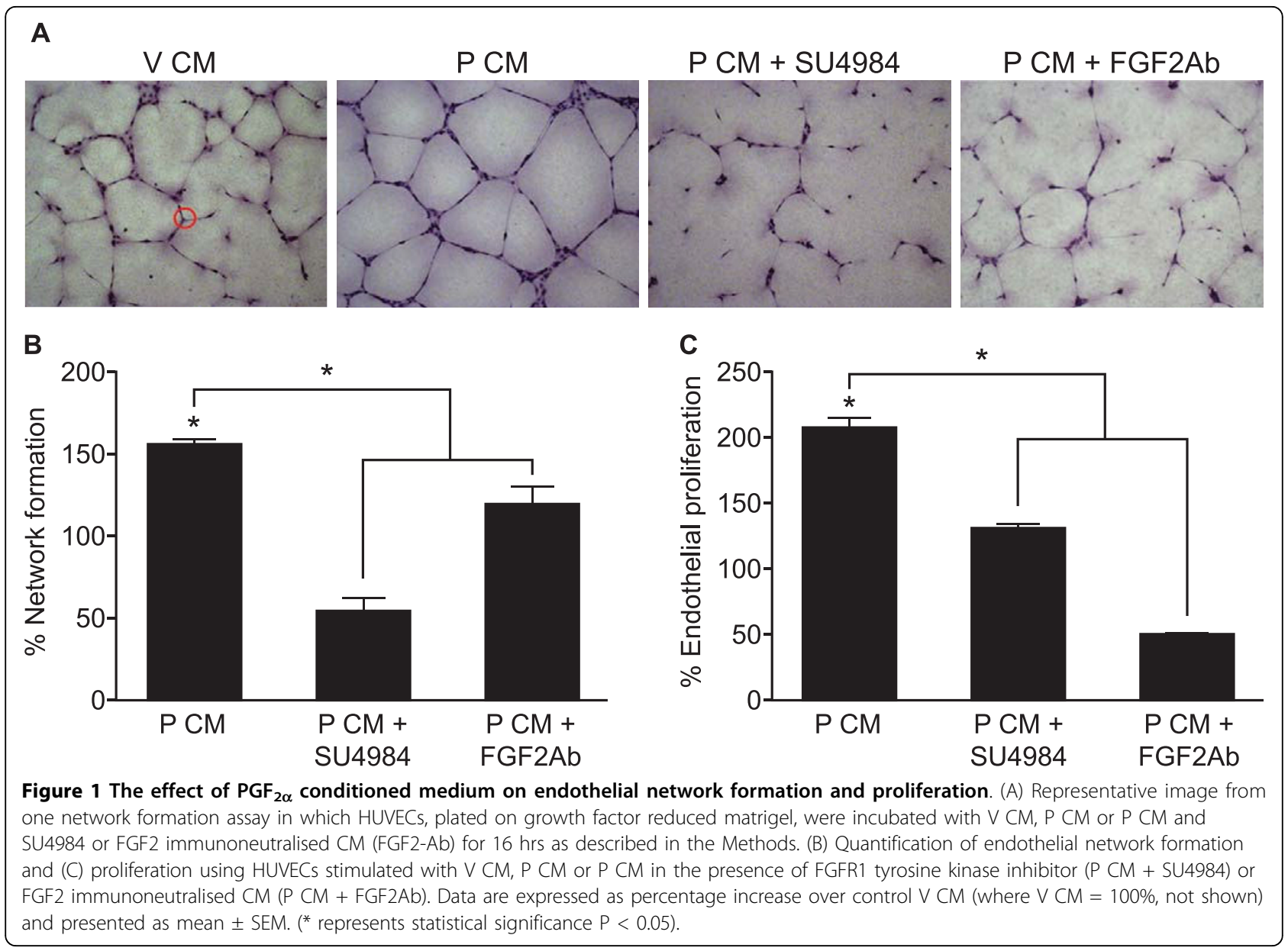

ERK1/2 phosphorylation in a time-dependent manner which was maximal after 10 mins of stimulation, compared to V CM (Fig. 3A; $\mathrm{P}<0.05$ ). Co-incubation of HUVECs with P CM in the presence of FGFR1 tyrosine kinase inhibitor (SU4984), c-Src inhibitor (PP2) or ERK1/2 inhibitor (PD98059) significantly reduced the P CM-stimulated phosphorylation of ERK1/2 to basal levels (Fig 3B, $\mathrm{P}<0.05$ ). However treatment of HUVECs with $\mathrm{P} C \mathrm{CM}$ in the presence of the PI3K inhibitor LY294002 did not significantly reduce the P CM phosphorylation of ERK1/2 (Fig. 3B). Similarly, co-incubation of HUVECs with P CM and the mTOR inhibitor, rapamycin, had no effect on ERK1/2 phosphorylation (data not shown). Treatment of HUVECs with recombinant FGF2 protein phosphorylated ERK1/2 to the levels observed with P CM (Fig. 3B).

Conditioned medium from Ishikawa FPS cell treated with PGF $_{2 \alpha}$ induces endothelial COX-2

FGF2 has been shown to mediate angiogenesis via COX2 in an in vivo model using rat sponge implants [17], hence we investigated the effect of $\mathrm{P} C \mathrm{CM}$ on the expression of COX-1 and COX-2 in endothelial cells. HUVECs were treated with V CM or P CM for 1, 2, 3, 4, 6, 16 and $24 \mathrm{hrs}$. We did not observe an alteration in the expression of COX-1 (Fig. 4A) at any of the time points investigated in response to P CM stimulation. However, we observed a significant increase in endothelial COX-2 expression at 3 hours following treatment with $\mathrm{P}$ CM (Fig. 4B; $\mathrm{P}<0.05$ ). This increase in COX-2 expression was inhibited by treatment with $\mathrm{P} \mathrm{CM}$ in the presence of the FGFR1 inhibitor, SU4984 or ERK1/2 inhibitor, PD98059 (Fig. 4C; $\mathrm{P}<0.05$ ) indicating that COX-2 expression was regulated via the FGF-2-FGFR1-ERK1/2 signalling pathway.

Cyclooxygenase enzymes are responsible for the catalysis of arachidonic acid to prostaglandins (PG). We next investigated the secretion of endothelial $\mathrm{PGE}_{2}$ and $\mathrm{PGF}_{2 \alpha}$ in response to CM treatment. HUVECs were treated with V CM or P CM for $0,3,6$, and $16 \mathrm{hrs}$ and the secretion of $\mathrm{PGE}_{2}$ (Fig. 4D) and $\mathrm{PGF}_{2 \alpha}$ (Fig. 4E) was measured by ELISA. There was no significant difference in the levels of endothelial $\mathrm{PGE}_{2}$ secreted by HUVECs in response to $\mathrm{CM}$ at any time point tested (Fig. 4D). In contrast, the amount of endothelial $\mathrm{PGF}_{2 \alpha}$ was elevated 


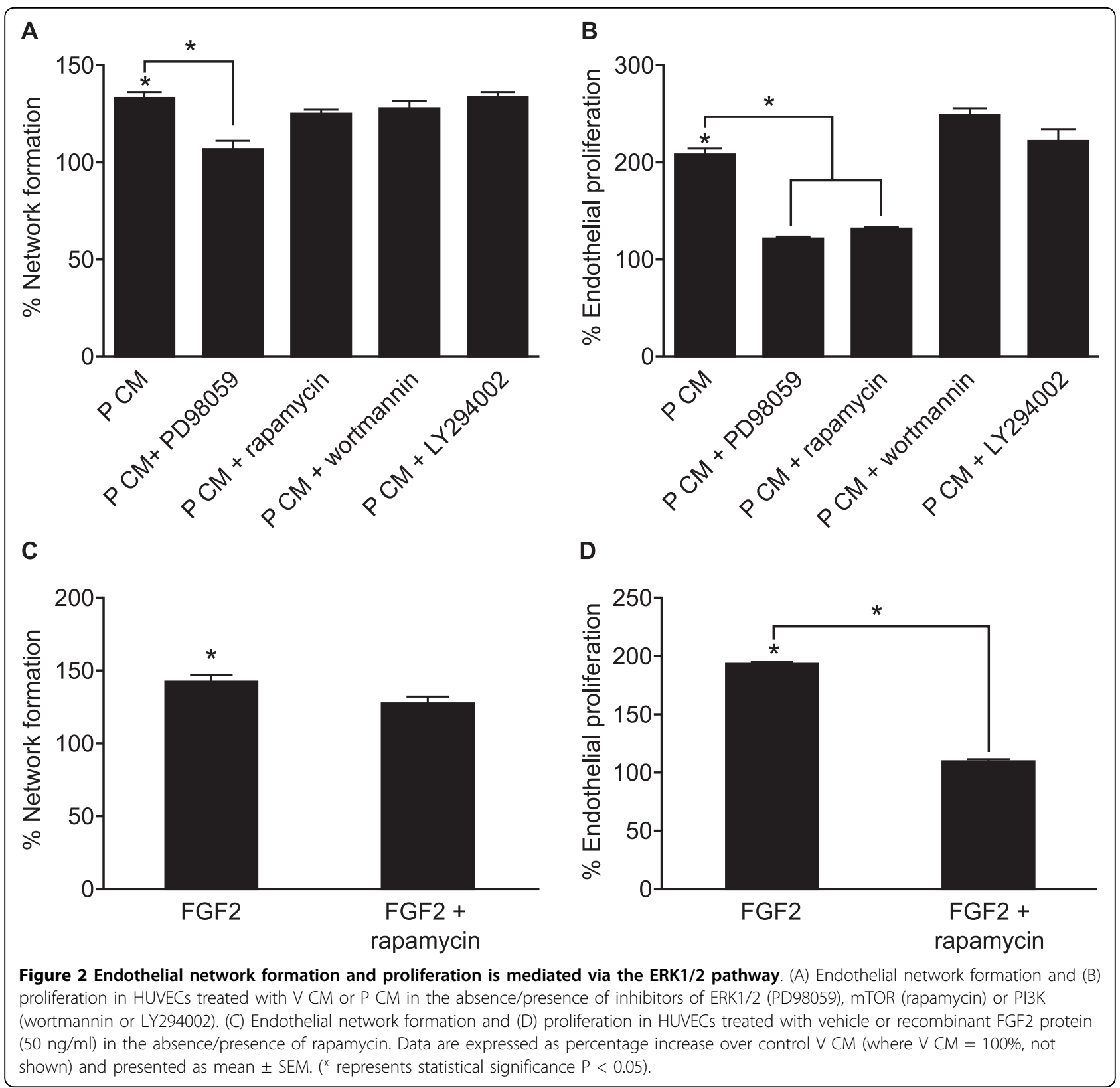

in HUVECs at 6 hrs following P CM treatment compared to both V CM treatment (6 hrs) and P CM at time 0 hrs (Fig. 4E; $\mathrm{P}<0.05$ ). To confirm the involvement of $\mathrm{COX}$ in the secretion of $\mathrm{PGF}_{2 \alpha}$, we treated HUVECs for $6 \mathrm{hrs}$ with P CM in the presence of the specific COX-2 inhibitor NS398 or the general COX inhibitor indomethacin. We found that the P CMinduced secretion of $\mathrm{PGF}_{2 \alpha}$ was significantly reduced by co-treatment of cells with NS398 (Fig. 4F; P $<0.05$ ). Similarly, co-treatment of cells with indomethacin significantly reduced $\mathrm{P}$ CM-induced $\mathrm{PGF}_{2 \alpha}$ secretion below the levels observed with $\mathrm{P} C \mathrm{CM}$ alone and $\mathrm{P} \mathrm{CM}$ with NS398 (Fig. 4F; $\mathrm{P}<0.05$ ).
The role of endothelial prostaglandin $F_{2 \alpha}$-FP signalling in the regulation of endothelial cell network formation

Since the secretion of $\mathrm{PGF}_{2 \alpha}$ was elevated in HUVECs following P CM treatment, we investigated the role of the F-prostaglandin receptor (FP) in endothelial cell function. We found a significant elevation in endothelial FP receptor expression after 3 hrs of treatment with $\mathrm{P}$ $\mathrm{CM}$ (Fig. 5A; $\mathrm{P}<0.05$ ). To determine if the regulation of $\mathrm{FP}$ receptor was mediated by FGF2 in the $\mathrm{P} C \mathrm{CM}$, we co-incubated HUVECs with P CM in the absence/presence of inhibitors of FGFR1 tyrosine kinase activity (SU4984) or ERK1/2 (PD98059). Incubation of HUVECs with P CM and SU4984 or PD98059 significantly 


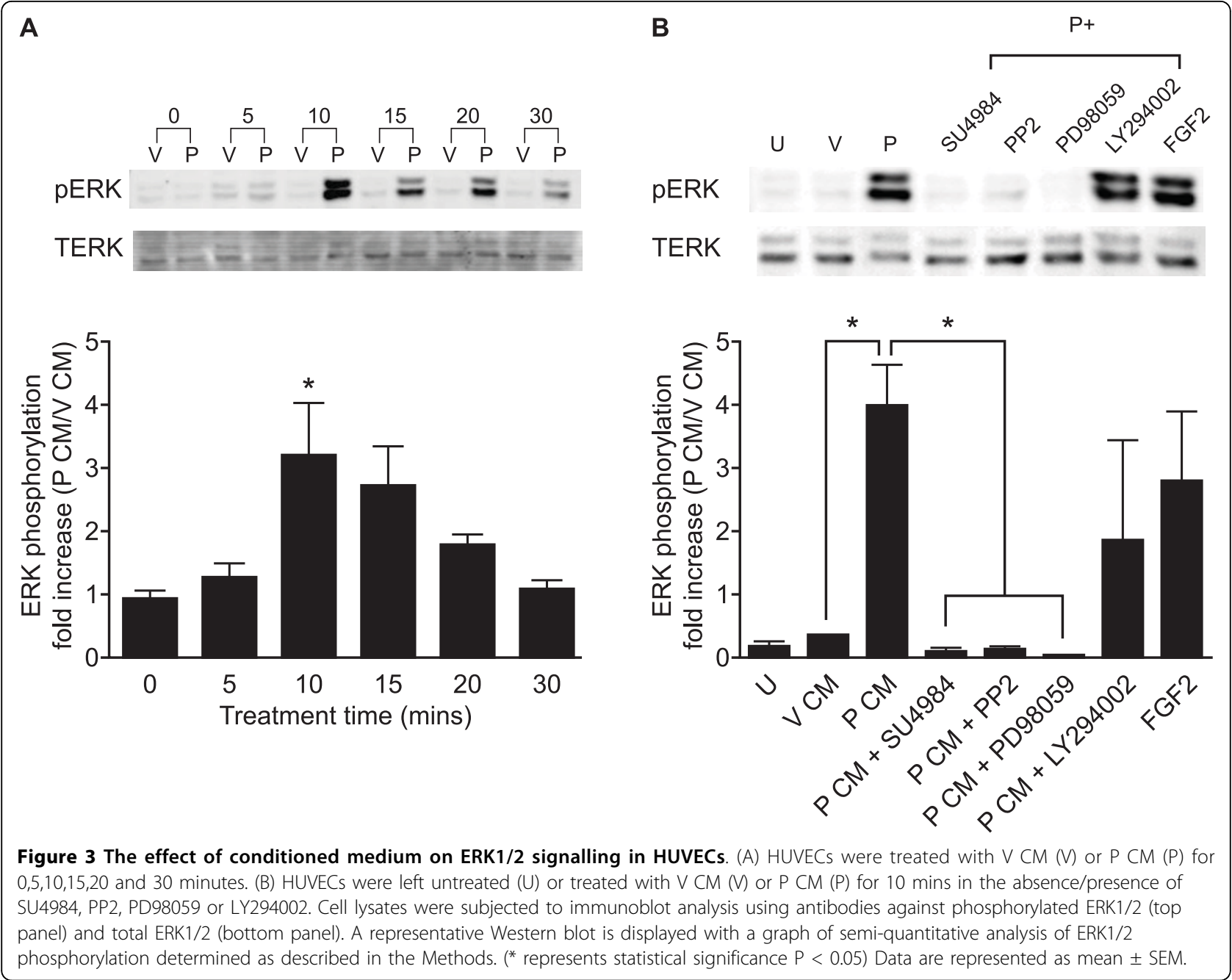

decreased the levels of FP receptor (Fig. 5B; $\mathrm{P}<0.05$ ) indicating that $\mathrm{FP}$ receptor expression was regulated by FGF2-FGFR1 interaction via the ERK1/2 pathway.

Next, as $\mathrm{PGF}_{2 \alpha}$ secretion and $\mathrm{FP}$ receptor expression was increased after P CM treatment, we explored the direct effect of $\mathrm{PGF}_{2 \alpha}$, acting via the $\mathrm{FP}$ receptor, on endothelial cell network formation and proliferation. We found that addition of $1 \mu \mathrm{M}$ exogenous $\mathrm{PGF}_{2 \alpha}$ significantly increased endothelial cell network formation (Fig. 5C; $\mathrm{P}<0.05$ ). In contrast, incubation of HUVECs with 1 $\mu \mathrm{M} \mathrm{PGF}_{2 \alpha}$ had no effect on endothelial cell proliferation (Fig. 5D). To investigate the autocrine/paracrine effect of $\mathrm{PGF}_{2 \alpha}-\mathrm{FP}$ receptor interaction in $\mathrm{P} \mathrm{CM}$-induced endothelial network formation, we used a short hairpin RNA (shRNA) adenoviral construct targeted against the FP receptor (sh478) to knockdown FP receptor expression in HUVECs. HUVECs were infected with scrambled adenovirus (scr) or sh478 for 24 hrs. Efficiency of the FP shRNA in ablating receptor expression was confirmed in the laboratory by quantitative RT-PCR and Western blot analysis (data not shown). Infection of HUVECs with sh478, significantly reduced P CMinduced network formation compared to scrambled control virus (Fig. 5E, $\mathrm{P}<0.05$ ). In contrast, infection of HUVECs with FP receptor shRNA adenovirus did not alter P CM-induced endothelial proliferation compared to HUVECs infected with the control scrambled adenovirus (Fig. 5F). Similar data were obtained using a second shRNA targeted to a different region of the FP receptor (sh306; data not shown). To confirm the role of COX-2 and FP receptor in endothelial cell network formation, HUVECs were treated with P CM in the absence or presence of the COX-2 inhibitor (NS398) or FP receptor antagonist (AL8810) (Fig 5G). Addition of NS398 or AL8810 significantly inhibited P CM-induced endothelial cell network formation (Fig 5G, P < 0.05).

\section{Discussion}

FGF2 is one of 23 fibroblast growth factor family members and signals via one of four receptors, FGFR1, 2, 3 


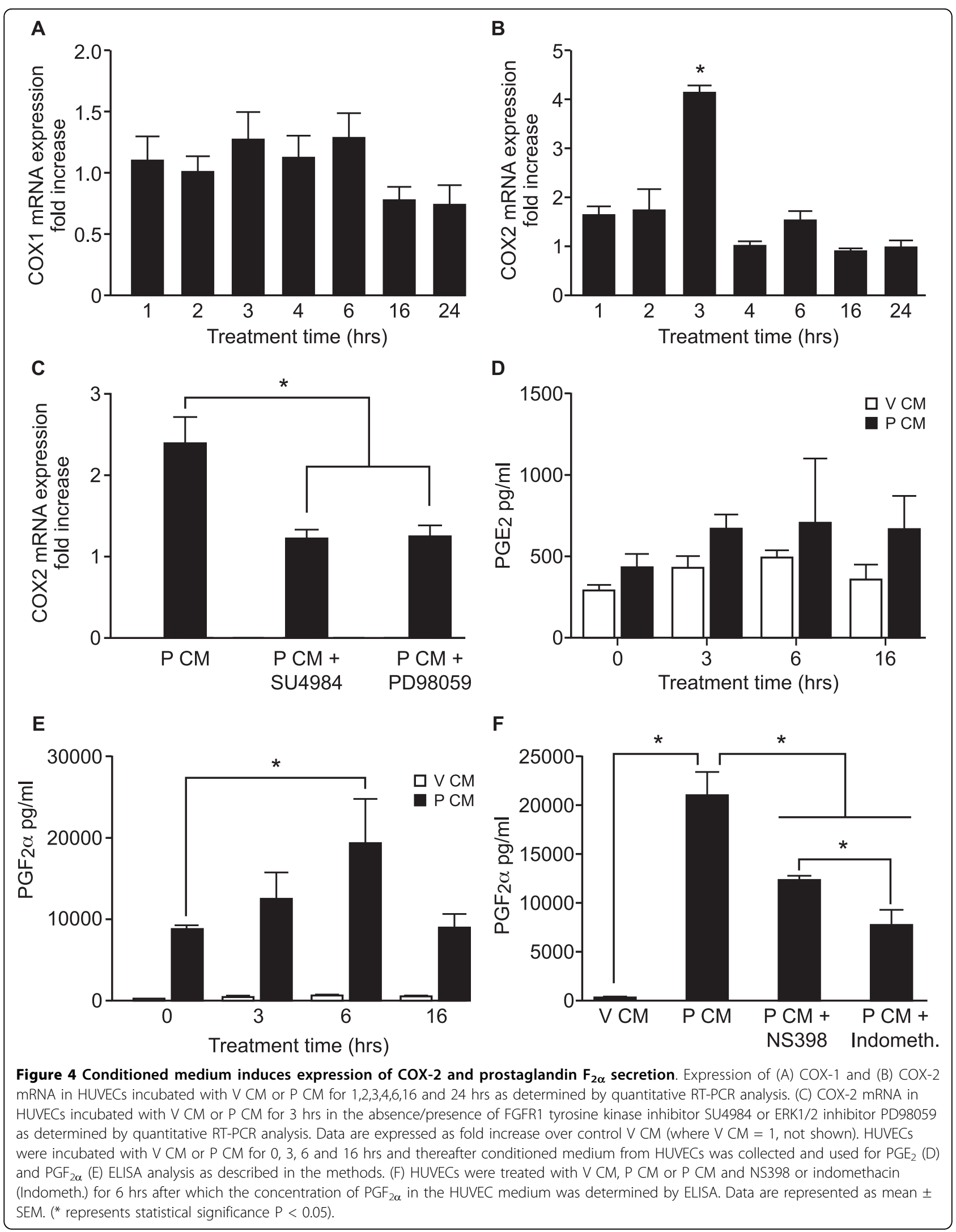



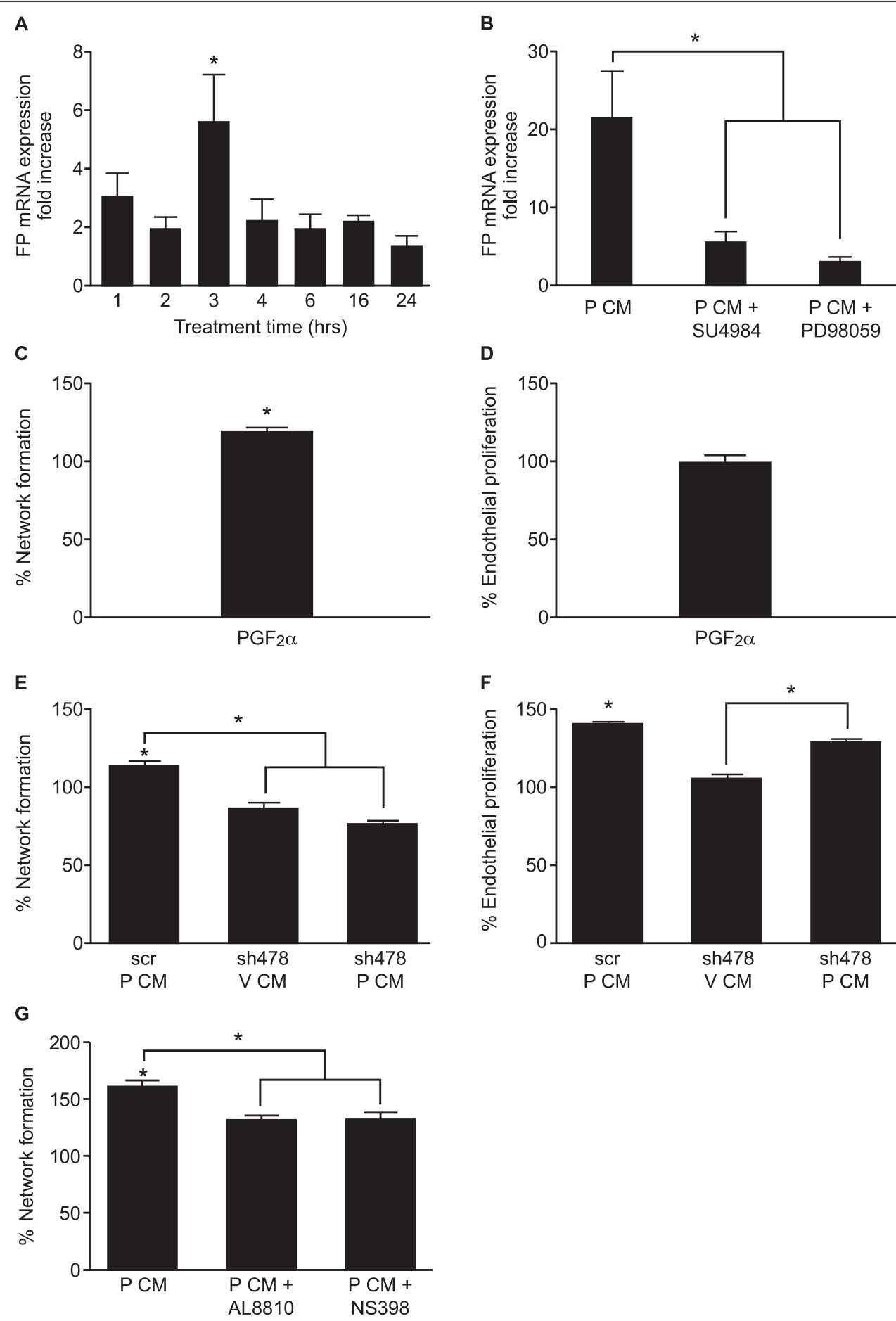

Figure 5 Endothelial network formation is regulated by endothelial PGF $_{2 \alpha}-$ FP receptor interaction. (A) Expression of FP receptor in HUVECs incubated with V CM or P CM for $1,2,3,4,6,16$ and 24 hrs as determined by quantitative RT-PCR analysis. (B) FP receptor mRNA in HUVECs incubated with V CM or P CM for 3 hrs in the absence/presence of FGFR1 tyrosine kinase inhibitor SU4984 or ERK1/2 inhibitor PD98059 as determined by quantitative RT-PCR analysis. HUVECs were incubated with vehicle or exogenous $\mathrm{PGF}_{2 \alpha}(1 \mu \mathrm{M})$ and endothelial cell network formation (C) and proliferation (D) were assessed. HUVECs were infected with scrambled adenovirus (scr) or short hairpin adenovirus targeted against the FP receptor (sh478) and treated with V CM or P CM. Endothelial network formation (E) and proliferation (F) was determined as described in the methods. (G) HUVECs were incubated with V CM or P CM in the absence/presence of NS398 or indomethacin and network formation was assessed. Data are expressed as fold or percentage increase over control V CM (V CM $=1$ or 100\%, not shown) and represented as mean \pm SEM. (* represents statistical significance $P<0.05$ ) 
and 4, of which FGFR1 is most commonly expressed on endothelial cells [18]. A principal role of secreted FGF2 is to stimulate blood vessel growth although we have shown previously that it can also act as a potent autocrine growth factor to enhance epithelial cell proliferation [12]. In vitro and animal xenograft studies have shown that secretion of epithelial FGF2 in endometrial adenocarcinoma xenografts can enhance tumour growth by enhancing blood vessel size and width [19]. Furthermore antisense targeting of FGF2 in such model systems is known to reduce tissue microvascular density as well as xenograft size [20].

Endothelial cell differentiation and proliferation are two of the processes required for angiogenesis $[11,21-23]$. In the present study we have shown that conditioned medium from endometrial adenocarcinoma cells, which stably express the FP receptor to the levels observed in endometrial adenocarcinomas (FPS cells) and produce FGF2, promotes endothelial network formation (differentiation) and proliferation. Using a specific FGFR1 tyrosine kinase inhibitor and FGF2immunoneutralised conditioned medium, we showed that the effects of conditioned medium on endothelial cell network formation and proliferation were via FGF2FGFR1 signalling. We found that although the FGF2immunoneutralised treatment inhibited network formation and proliferation, it was less effective than the FGFR1 inhibitor SU4984. We believe this difference lies in the residual FGF2 remaining in the FGF2-immunoneutralised CM after neutralisation [12] which could, albeit to a lesser extent, activate the FGF receptor on HUVECs.

To explore the signalling pathways activated in HUVECs by FGF2, following its release from epithelial cells in response to $\mathrm{PGF}_{2 \alpha}$-FP receptor activation, we used small molecule chemical inhibitors of intracellular signalling pathways. We found that conditioned medium from $\mathrm{PGF}_{2 \alpha}$-treated Ishikawa FPS cells enhanced endothelial cell network formation via FGFR1 and ERK1/2 independently of PI3K and mTOR. This is in agreement with the observations of Kanda et al. [24], who demonstrated in murine brain endothelial cells that FGF2 induced endothelial network formation is not dependent on activation of the mTOR pathway [24] and Sulpice et al [25] who showed that, in adrenal cortex capillary endothelial cells, ERK1/2 phosphorylation induced by recombinant FGF2 is not mediated via the PI3K pathway [25]. Similarly, Peng et al. showed that FGF2 treatment can induce mTOR phosphorylation in HUVECs [26].

In contrast, we found that conditioned mediuminduced endothelial cell proliferation was dependent on ERK1/2 signalling to mTOR as endothelial cell proliferation could be inhibited with the ERK1/2 kinase inhibitor
PD98059 and rapamycin, but not the PI3K inhibitors wortmannin or LY294002. This is in agreement with previous studies showing that the ERK1/2 inhibitor PD98059 can inhibit FGF2- induced angiogenesis [27] and HUVEC proliferation [28]. Our data indicate that endothelial network formation and proliferation are regulated by distinct signal transduction pathways which are integrated by ERK1/2 signalling.

ERK1/2 is known to be a potent regulator of cell growth, differentiation and development [29]. Once phosphorylated, ERK1/2 can translocate to the nucleus and promote gene transcription [29]. The phosphorylation and activation of ERK1/2 can be modulated via a multitude of intracellular signal transduction pathways. Hence, we investigated conditioned medium signalling to ERK1/2 in HUVECs and found within our experimental paradigm that ERK1/2 was phosphorylated in a time dependent manner. The fact that ERK $1 / 2$ is activated by $\mathrm{P} C \mathrm{CM}$ and that the ERK1/2 inhibitor abolished ERK1/2 phosphorylation, as well as endothelial network formation and proliferation, suggests that ERK1/2 could act as a major transcriptional regulator in this model system. This phosphorylation and activation of ERK1/2 was found to be regulated via FGFR1 signalling to c-Src, since co-treatment of HUVECs with P CM and the FGFR1 inhibitor SU4984 or cSrc inhibitor PP2 significantly inhibited ERK phosphorylation. Furthermore ERK1/2 phosphorylation was found to be independent of PI3K and mTOR as neither the PI3K inhibitor LY294002 nor the mTOR inhibitor rapamycin (data not shown) inhibited P CM-induced ERK1/2 phosphorylation. c-Src is a protein tyrosine kinase which co-ordinates a diverse spectrum of receptor-induced signalling to ERK1/2 via the phosphorylation of signalling intermediates such as Ras and Raf [30]. c-Src has been shown to be involved in FGF-2 induced angiogenesis [31] and a recent study has shown that c-Src, Raf and ERK1/2 are essential for HUVEC lumen formation in vitro [32]. These data suggest that the FGF2-FGFR1-cSrc pathway plays a role in the activation of ERK1/2 by $\mathrm{P}$ CM treatment.

Following ERK1/2 activation, mTOR has been shown to be regulated via the tuberous sclerosis complex 1 and 2 (TSC1/2 also called Hamartin and Tuberin) [33,34]. Phosphorylation of TSC2 by ERK1/2 results in its dissociation from TSC1 and its subsequent degradation via the ubiquitin pathway. This inactivates the inhibitory effect of TSC1/2 on the mTOR pathway and allows cellular proliferation to proceed [35].

Over the past decade several reports have highlighted the importance of COX enzymes and prostaglandins in regulating vascular function indirectly. This may occur via the activation of ERK1/2 signalling resulting in epithelial or stromal cell production of pro-angiogenic 
factors which act in a paracrine manner on endothelial cells [4,36,37]. This is in agreement with our observations here whereby FGF2, released by Ishikawa FPS cells in response to $\mathrm{PGF}_{2 \alpha}$, enhanced the expression of COX2 in endothelial cells via the FGF2-FGFR1-ERK1/2 pathway. Similarly, FGF2 has been shown to upregulate endothelial COX-2 in murine cerebral microvascular cells leading to an increase in prostaglandin $E_{2}$ production [38].

Prostaglandins have been shown to be secreted by endothelial cells and to influence directly endothelial cell function via their receptors on endothelial cells [39-41]. These studies showed that $\mathrm{PGE}_{2}$ present in the endothelial environment can enhance endothelial cell functions [38-41], however in our study we found no significant elevation in $\mathrm{PGE}_{2}$ biosynthesis in response to P CM. Instead, we found that endothelial cells secrete elevated levels of $\mathrm{PGF}_{2 \alpha}$ following activation by $\mathrm{CM}$ from $\mathrm{PGF}_{2 \alpha}$-treated Ishikawa FPS cells and that this $\mathrm{PGF}_{2 \alpha}$ secretion was regulated via the FGF2-FGFR1ERK1/2-mediated induction of COX-2 since the specific COX-2 inhibitor significantly reduced $\mathrm{PGF}_{2 \alpha}$ secretion. In order to determine whether $\mathrm{COX}-1$ contributed towards the generation of $\mathrm{PGF}_{2 \alpha}$, a general COX inhibitor indomethacin was used. Co-treatment of cells with indomethacin significantly reduced $\mathrm{PGF}_{2 \alpha}$ secretion to a level below that observed for the specific COX-2 inhibitor suggesting that basal levels of COX-1 may, to a lesser extent, contribute towards the secretion of $\mathrm{PGF}_{2 \alpha}$. These data indicate that although $\mathrm{PGE}_{2}$ is secreted in higher quantities than $\mathrm{PGF}_{2 \alpha}$ by unstimulated HUVECs [42], under P CM stimulated conditions, prostaglandin $\mathrm{F}_{2 \alpha}$ is the predominant COX-2 product. Furthermore, this suggests that the endothelial signalling pathways induced by FGF2 are context dependent, i.e. dependent on the nature of the external stimulus, such as cancer conditioned medium, from which the FGF2 originates. We found exogenous prostaglandin $F_{2 \alpha}$ was able to stimulate endothelial cell network formation but not proliferation. Interestingly, the effect of exogenous $\mathrm{PGF}_{2 \alpha}$ on network formation was less than that observed for $\mathrm{P}$ $\mathrm{CM}$. We believe that the higher levels of FP receptor in endothelial cells induced by P CM accounts for this difference. It is likely that the upregulated FP receptor in $\mathrm{P}$ CM treated HUVECs would enable a greater signalling capacity and ability to form networks compared with HUVECs treated with exogenous $\mathrm{PGF}_{2 \alpha}$ alone in the absence of growth factors, where FP receptor expression is not induced. Using a specific FP receptor short hairpin RNA (FP shRNA) in an adenoviral delivery system for targeted ablation of endothelial FP receptor, we found that P CM-induced endothelial network formation was regulated by the endothelial FP receptor. In addition, the use of a chemical inhibitor against COX-2 and a specific FP receptor antagonist further confirmed a role for endothelial $\mathrm{PGF}_{2 \alpha}$ signalling through the endothelial FP receptor in the regulation of $\mathrm{P}$ CMinduced endothelial cell network formation.

\section{Conclusions}

As summarised in fig. 6, our data show that $\mathrm{PGF}_{2 \alpha}-\mathrm{FP}$ receptor signalling in endometrial adenocarcinoma cells produces FGF2, which acts in a paracrine manner on endothelial FGFR1 to promote endothelial cell differentiation and proliferation via distinct intracellular mechanisms. We demonstrate a novel mechanism whereby FGF2 induces the secretion of prostaglandin $\mathrm{F}_{2 \alpha}$ to regulate P CM-induced endothelial cell differentiation. This the first study to show, with FP shRNA, that endothelial FP receptors can mediate endothelial cell differentiation but not proliferation. We believe that these findings have relevance for endometrial pathologies, such as endometrial adenocarcinoma, which have aberrant expression of FP receptor and we propose a molecular mechanism whereby FP receptor may regulate vascular function $[13,43]$. Furthermore our data suggest that targeted antagonism of epithelial FP receptor signalling, to reduce the production of growth factors, or endothelial FP receptor signalling, to prevent differentiation of endothelial cells, could provide an anti-angiogenic approach to reducing tumour vasculature and growth.

\section{Methods \\ Reagents}

The FGF2 antibody recognising the $18 \mathrm{kDa}$ isoform of FGF2 (sc1360) was purchased from Santa Cruz Biotechnology (Autogen-Bioclear, Wiltshire, UK). Arachidonic acid (AA), $\mathrm{PGF}_{2 \alpha}$ and indomethacin were purchased from Sigma Chemical Co. (Dorset, UK). PD98059, SU4984, LY294002, PP2, NS398, wortmannin and rapamycin were purchased from Calbiochem (Nottingham, UK). Recombinant FGF2 peptide was purchased from PeproTechEC Ltd. (London, UK). Anti-phospho-p42/44 ERK and anti-p42/p44 ERK were purchased from Cell Signalling Technologies/New England Biolabs (Hertfordshire, UK).

\section{Cell culture}

Ishikawa cells stably expressing FP receptor (Ishikawa FPS cells) were cultured in Dulbecco's Modified Eagle's Medium (DMEM, Invitrogen, Paisley, UK) with 10\% foetal bovine serum (FBS) and 1\% penicillin/streptomycin as described previously [13]. Human umbilical vein endothelial cells (HUVECs) (Lonza, Walkersville, USA) were cultured in Endothelial Basal Medium (EBM-2) with $2 \%$ FBS and growth supplements (VEGF, FGF, PGDF, IGF, EGF, ascorbic acid, heparin and gentamycin) subsequently referred to as Endothelial Growth 


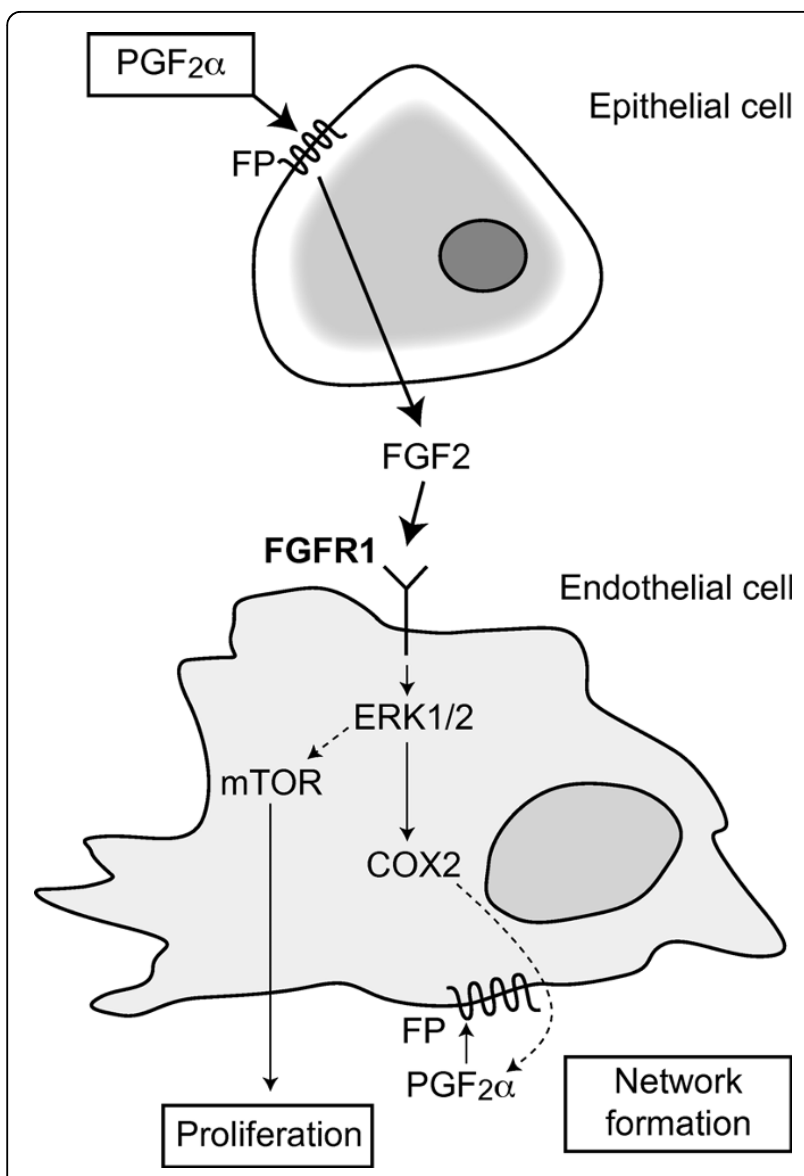

Figure $6 \mathrm{~A}$ schematic representation of $\mathrm{PGF}_{2 \alpha}-\mathrm{FP}$ receptor signalling which differentially regulates endothelial network formation and proliferation. $\mathrm{PGF}_{2 \alpha}$-FP receptor signalling in epithelial cells promotes the release of FGF2 into culture medium (conditioned medium). Conditioned medium treatment of HUVECS promotes the activation of ERK1/2 signalling via the FGF2-FGFR1. ERK1/2 activates divergent signalling pathways to endothelial proliferation and network formation. Endothelial proliferation is activated via mTOR. Endothelial network formation is activated via the induction of endothelial COX-2 enhancing the biosynthesis and release of $\mathrm{PGF}_{2 \alpha}$. Endothelial $\mathrm{PGF}_{2 \alpha}$ subsequently acts on endothelial FP receptors to promote network formation (endothelial differentiation).

Medium (EGM-2) (Lonza, Walkersville, USA). Under experimental conditions HUVECs were incubated with EBM-2 containing $1 \%$ fetal bovine serum (FBS) with the addition of ascorbic acid and gentamycin (EBM1\%) (Lonza, USA). Cell viability in the presence of chemical compounds used to inhibit specific signal transduction pathways was assessed using the CellTitre96AQueous One Solution Proliferation Reagent (Promega, Southampton, UK).

\section{Conditioned medium}

Conditioned medium (CM) was prepared as described previously [12]. Briefly, FPS cells were seeded at a density of $2 \times 10^{6}$ cells and allowed to adhere before serum-starvation for $24 \mathrm{hrs}$. Thereafter, cells were treated with $20 \mathrm{mls}$ of DMEM containing $8.4 \mu \mathrm{M}$ indomethacin in the presence of $100 \mathrm{nM} \mathrm{PGF}_{2 \alpha}$ or vehicle for 24 hrs to create $\mathrm{PGF}_{2 \alpha}$ conditioned medium (P CM) or vehicle conditioned medium (V CM). Conditioned medium from three independent experiments was pooled, aliquoted and stored at $-20^{\circ} \mathrm{C}$ until required. FGF2 was immunoneutralised from the $\mathrm{PGF}_{2 \alpha}$ conditioned medium by overnight incubation with $0.5 \mu \mathrm{g} / \mathrm{ml}$ FGF2 antibody. The immune complex was removed by $4 \mathrm{hr}$ incubation with $20 \mu \mathrm{l}$ of a $50 \%$ protein A plus G slurry (Calbiochem). Conditioned medium immunoneutralised with Goat IgG was used as a control. Immunoneutralised $\mathrm{CM}$ was aliquoted and stored at $-20^{\circ} \mathrm{C}$ until use. The FGF2 content in the CM before and after immunoneutralisation was confirmed by ELISA as described previously [12].

\section{Network assays}

Network assays were carried out using 12-well Transwell plates (Corning Costar, Cambridge, UK). The upper chambers were coated with $80 \mu \mathrm{l}$ of growth factor (GF)reduced Matrigel (BD Biosciences, MA, USA) in the absence/presence of SU4984 (20 $\mu \mathrm{M})$, PD98059 (50 $\mu \mathrm{M})$, rapamycin $(100 \mathrm{ng} / \mathrm{ml})$, wortmannin $(200 \mathrm{nM})$, LY294002 $(50 \mu \mathrm{M})$, NS398 $(10 \mu \mathrm{M})$ or AL8810 $(50 \mu \mathrm{M})$ and incubated at $37^{\circ} \mathrm{C}$ for 30 mins to allow thin gel formation. HUVECs were plated onto the gel $\left(2.5 \times 10^{4}\right.$ cells/well) in EBM 1\%. In the lower chamber V CM or $\mathrm{P} C \mathrm{CM}$ was added. Transwell plates were incubated at $37^{\circ} \mathrm{C}$ in a $5 \% \mathrm{CO}_{2}$ atmosphere for $16 \mathrm{hrs}$. Subsequently, cell networks were fixed with $100 \%$ ice cold methanol and stained with haematoxylin. To assess network formation, each well was divided into 5 sections. Hotspots of each section were photographed, 5 photos per well at $\times 10$ magnification, using an inverted microscope and camera (Axiovert 200, Carl Zeiss, Germany). The number of network branches was counted blind. Experiments were repeated at least four times in duplicate. Fold difference was determined by dividing the value obtained from P CM treated cells by the value obtained from V CM treated cells. Data were transformed to percentage increase in network formation with $\mathrm{V} \mathrm{CM}=$ $100 \%$ and are presented as mean \pm SEM.

\section{Proliferation assay}

HUVECs were seeded in 96-well plates at 3000 cells/ well. Following attachment, cell medium was replaced with EBM1\% for 3 hours. Cells were then treated with $\mathrm{CM}$, diluted 1:1 (v/v) with EBM1\%, in the absence/presence of SU4984, PD98059, rapamycin, wortmannin, LY294002 or FGF2-immunoneutralised CM. Treatments were replaced three times during the $96 \mathrm{hr}$ incubation. Proliferation was determined using the CellTitre96AQueous One Solution Proliferation Reagent (Promega) as per the manufacturer's instructions. The experiments 
were repeated three times in quadruplicate. Fold difference was determined by dividing the absorbance obtained by P CM treated cells by the absorbance obtained by V CM treated cells. Data were transformed to percentage increase in proliferation with $\mathrm{V} \mathrm{CM}=$ $100 \%$ and are presented as mean \pm SEM.

\section{Western Blot analysis}

HUVECs were seeded at $2 \times 10^{5}$ cells per $60 \mathrm{~mm}$ diameter dish and left to adhere for 24 hrs before GF-starvation overnight. The next day, HUVECs were treated with P CM or V CM for the time indicated in the figure legend, rinsed with ice-cold phosphate-buffered saline and lysed for 20 mins with protein lysis buffer containing inhibitor cocktail mix as described previously [43]. Protein concentration was determined with a protein assay (BioRad, Hercules, CA) and approximately $16 \mu \mathrm{g}$ of protein was resolved and immunoblotted as previously described [44]. Immunoblots were blocked in Odyssey Blocking buffer ${ }^{\mathrm{TM}}$ (LI-COR Biosciences, Cambridge, UK) before overnight incubation with primary phospho-p42/44 and p42/44 antibodies (diluted 1:1000 in Odyssey blocking buffer) at $4{ }^{\circ} \mathrm{C}$. The following day, blots were washed and incubated with the goat antimouse IRDye ${ }^{\mathrm{Tm}} 800$ (1:10,000) (Rockland Immunochemicals Inc., Gilbertsville, PA, USA) and goat anti-rabbit Alexafluor 680 (1:5000) (Invitrogen) for 60 minutes at room temperature. Immunoreactive proteins were detected and quantified using the Odyssey infrared imaging system (LI-COR Biosciences). ERK1/2 phosphorylation was calculated by dividing the value obtained from the phosphorylated ERK1/2 channel $(700 \mathrm{~nm})$ by the value obtained from total ERK1/2 channel $(800 \mathrm{~nm})$ and expressed as fold above vehicle controls. Results are expressed as mean \pm SEM from at least four independent experiments.

\section{Taqman quantitative RT-PCR}

Taqman RT-PCR was performed as described previously using sequence specific primers and probes designed to span an intron $[43,45,46]$. Briefly, HUVECs were seeded at $5 \times 10^{4}$ cells per well with EBM1\% in a 6 well plate. Following overnight serum starvation, cells were treated with V CM or P CM, diluted 1:1 (v/v) with EBM 1\% in the absence or presence of SU4984 $(20 \mu \mathrm{M})$ or PD98059 $(50 \mu \mathrm{M})$ for the time indicated in the figure legends. RNA was extracted, reverse transcribed and RT-PCR performed using the ABI Prism 7900 as described previously [12]. COX-1, COX-2 and FP mRNA were normalized using ribosomal $18 \mathrm{~S}$ as an internal control. Experiments are representative of at least five independent experiments. Fold difference was determined by dividing the value obtained from P CM treated cells by the value obtained from V CM treated cells and represented as mean \pm SEM.

\section{$\mathrm{PGF}_{2 \alpha} / \mathrm{PGE}_{2}$ ELISA}

HUVECs were seeded at a density of $5 \times 10^{4}$ cells per $35 \mathrm{~mm}$ diameter dish and serum starved overnight. Thereafter cells were treated with V CM or P CM diluted 1:1 (v/v) with EBM 1\% containing $3 \mu \mathrm{g} / \mathrm{ml}$ arachidonic acid for the time indicated in the figure legend. After treatment $\mathrm{CM}$ was collected and stored at $-20^{\circ} \mathrm{C}$ until required. $\mathrm{PGF}_{2 \alpha}$ and $\mathrm{PGE}_{2}$ secretions in the culture media were assayed by ELISA as described previously $[47,48]$. When using chemical inhibitors, cells were preincubated with EBM1\% and NS398 $(10 \mu \mathrm{M})$ or indomethacin $(8.4 \mu \mathrm{M})$ for 30 minutes and subsequently, cells were treated with V CM or P CM in the absence or presence of inhibitors with the addition of $3 \mu \mathrm{g} / \mathrm{ml}$ arachidonic acid for 6 hrs. Experiments were repeated three times. The data are presented as mean \pm SEM.

\section{Short hairpin DNA constructs and preparation of} adenoviral stocks

To generate FP receptor knockdown vectors, oligonucleotides encoding short hairpin transcripts were annealed and individually cloned into the adenovirus shuttle vector pDC316. The start codon of the FP receptor (NM_000959) was used as a reference and labelled as basepair 1 . Thus the target sequences corresponded to 478 bp downstream and included a scrambled (scr) negative control: Sh478: 5'-GTGGCCTGGTAATCACTGA; scr: 5'-TTACTCGACGCATGTGCTT. High titre stocks $(<10 \mathrm{e} 10$ viral plaque forming units $/ \mathrm{ml}, \mathrm{pfu} /$ $\mathrm{ml}$ ) were prepared using the AdMax system (Microbix Biosystems Inc., Toronto, Ontario, Canada). Briefly, an adenovirus genomic plasmid (pBHGLoxdeltaE1,3Cre) was cotransfected with the shuttle vector into HEK293 cells. After 10 days, plaques were purified and seeded into a T75 flask of HEK293 to generate the first seed. When HEK293 cells showed a cytopathic response; virus was released from the cells by three cycles of freeze thawing. This starter culture was used to produce large bulk preparations of adenovirus. Viral particles were purified using a Vivascience AdenoPack column (Generon House, Eton Wick, UK), buffer exchanged into 8 volumes of $2.5 \%$ glycerol, $20 \mathrm{mM}$ Tris- $\mathrm{HCl}(\mathrm{pH} 8)$ and then concentrated. The viral titre was determined using a modified Adeno-X rapid titre kit (Clontech-Takara Bio Europe, Saint-Germain-en-Laye, France) with 1:1000 rabbit anti-adenovirus Serotype 5 hexon antisera (Labfrontier, Seoul, Korea).

To ablate FP receptor expression, HUVECs were seeded at a density of $3 \times 10^{5}$ cells $/ 25 \mathrm{~cm}^{2}$ in EGM-2 and incubated with 100 viruses (either scr or sh478) per cell (MOI) for $24 \mathrm{hrs}$ at $37^{\circ} \mathrm{C}$ in a $5 \% \mathrm{CO}_{2}$ atmosphere. The next day, the viral infected cells were washed, trypsinised, counted and used in the network formation and proliferation assays. 


\section{Statistics}

Statistical significance was assessed on untransformed data with one-way ANOVA and Dunnett's post hoc test using Prism 5.0 (Graph Pad, San Diego, CA). A p-value of less than $0.05(\mathrm{P}<0.05)$ was considered to be statistically significant.

\section{Acknowledgements}

The authors would like to thank Dr James Logie for helpful advice and technical assistance. This study was supported by MRC core funding to HNJ (U.1276.00.004.00002.01)

\section{Authors' contributions}

MCK carried out the main part of the experiments, participated in the design, statistical analysis, drafting and writing of the manuscript. PB produced the short hairpin DNA constructs and preparation of adenoviral stocks. HNJ conceived the study and helped to draft the manuscript. KJS conceived the study, and participated in its design and coordination and helped to draft the manuscript. All authors read and approved the final manuscript.

Received: 12 August 2009

Accepted: 21 January 2010 Published: 21 January 2010

\section{References}

1. Westlake S, Cooper N: Cancer incidence and mortality: trends in the United Kingdom and constituent countries, 1993 to 2004. Health Stat Q 2008, , 38: 33-46.

2. Jemal A, Siegel R, Ward E, Hao Y, Xu J, Murray T, Thun MJ: Cancer statistics, 2008. CA Cancer J Clin 2008, 58(2):71-96.

3. Doll A, Abal M, Rigau M, Monge M, Gonzalez M, Demajo S, Colás E, Llauradó M, Alazzouzi H, Planagumá J, Lohmann MA, Garcia J, Castellvi S, Ramon y Cajal J, Gil-Moreno A, Xercavins J, Alameda F, Reventós J: Novel molecular profiles of endometrial cancer-new light through old windows. J Steroid Biochem Mol Biol 2008, 108(3-5):221-229.

4. Jabbour HN, Sales KJ, Smith OP, Battersby S, Boddy SC: Prostaglandin receptors are mediators of vascular function in endometrial pathologies. Mol Cell Endocrinol 2006, 252(1-2):191-200.

5. Tong BJ, Tan J, Tajeda L, Das SK, Chapman JA, DuBois RN, Dey SK: Heightened expression of cyclooxygenase-2 and peroxisome proliferator-activated receptor-delta in human endometrial adenocarcinoma. Neoplasia 2000, 2(6):483-490.

6. Tsuji S, Kawano S, Sawaoka H, Takei Y, Kobayashi I, Nagano K, Fusamoto H, Kamada T: Evidences for involvement of cyclooxygenase-2 in proliferation of two gastrointestinal cancer cell lines. Prostaglandins Leukot Essent Fatty Acids 1996, 55(3):179-183.

7. Tsujii M, DuBois RN: Alterations in cellular adhesion and apoptosis in epithelial cells overexpressing prostaglandin endoperoxide synthase 2 . Cell 1995, 83(3):493-501.

8. Tsujii M, Kawano S, Tsuji S, Sawaoka H, Hori M, DuBois RN: Cyclooxygenase regulates angiogenesis induced by colon cancer cells. Cell 1998, 93(5):705-716.

9. Folkman J: Tumor angiogenesis: therapeutic implications. N Engl J Med 1971, 285(21):1182-1186.

10. Bergers G, Benjamin LE: Tumorigenesis and the angiogenic switch. Nat Rev Cancer 2003, 3(6):401-410.

11. Ausprunk DH, Folkman J: Migration and proliferation of endothelial cells in preformed and newly formed blood vessels during tumor angiogenesis. Microvasc Res 1977, 14(1):53-65.

12. Sales KJ, Boddy SC, Williams AR, Anderson RA, Jabbour HN: F-prostanoid receptor regulation of fibroblast growth factor 2 signalling in endometrial adenocarcinoma cells. Endocrinology 2007, 148(8):3635-3644.

13. Sales KJ, List T, Boddy SC, Williams AR, Anderson RA, Naor Z, Jabbour HN: A novel angiogenic role for prostaglandin F2alpha-FP receptor interaction in human endometrial adenocarcinomas. Cancer Res 2005, 65(17):7707-7716.
14. Soufla G, Sifakis S, Spandidos DA: FGF2 transcript levels are positively correlated with EGF and IGF-1 in the malignant endometrium. Cancer Lett 2008, 259(2):146-155.

15. Danielsen T, Rofstad EK: VEGF, bFGF and EGF in the angiogenesis of human melanoma xenografts. Int J Cancer 1998, 76(6):836-841.

16. Rofstad EK, Halsor EF: Vascular endothelial growth factor, interleukin 8 , platelet-derived endothelial cell growth factor, and basic fibroblast growth factor promote angiogenesis and metastasis in human melanoma xenografts. Cancer Res 2000, 60(17):4932-4938.

17. Majima M, Hayashi I, Muramatsu M, Katada J, Yamashina S, Katori M: Cyclooxygenase- 2 enhances basic fibroblast growth factor-induced angiogenesis through induction of vascular endothelial growth factor in rat sponge implants. Br J Pharmacol 2000, 130(3):641-649.

18. Auguste $P$, Javerzat $S$, Bikfalvi A: Regulation of vascular development by fibroblast growth factors. Cell Tissue Res 2003, 314(1):157-166.

19. Konerding MA, Fait E, Dimitropoulou C, Malkusch W, Ferri C, Giavazzi R, Coltrini D, Presta M: Impact of fibroblast growth factor-2 on tumor microvascular architecture. A tridimensional morphometric study. Am J Pathol 1998, 152(6):1607-1616.

20. Wang $Y$, Becker $D$ : Antisense targeting of basic fibroblast growth factor and fibroblast growth factor receptor-1 in human melanomas blocks intratumoral angiogenesis and tumor growth. Nat Med 1997, 3(8):887-893.

21. Folkman J, Haudenschild C: Angiogenesis in vitro. Nature 1980, 288(5791):551-556

22. Hanahan D, Folkman J: Patterns and emerging mechanisms of the angiogenic switch during tumorigenesis. Cell 1996, 86(3):353-364.

23. Adams RH, Alitalo K: Molecular regulation of angiogenesis and lymphangiogenesis. Nat Rev Mol Cell Biol 2007, 8(6):464-478.

24. Kanda S, Hodgkin MN, Woodfield RJ, Wakelam MJ, Thomas G, ClaessonWelsh L: Phosphatidylinositol 3'-kinase-independent p70 S6 kinase activation by fibroblast growth factor receptor- 1 is important for proliferation but not differentiation of endothelial cells. J Biol Chem 1997, 272(37):23347-23353

25. Sulpice E, Bryckaert M, Lacour J, Contreres JO, Tobelem G: Platelet factor 4 inhibits FGF2-induced endothelial cell proliferation via the extracellular signal-regulated kinase pathway but not by the phosphatidylinositol 3kinase pathway. Blood 2002, 100(9):3087-3094.

26. Peng $C Y$, Pan $S L$, Lee KH, Bastow KF, Teng CM: Molecular mechanism of the inhibitory effect of KS-5 on bFGF-induced angiogenesis in vitro and in vivo. Cancer Lett 2008, 263(1):114-121.

27. Eliceiri BP, Klemke R, Stromblad S, Cheresh DA: Integrin alphavbeta3 requirement for sustained mitogen-activated protein kinase activity during angiogenesis. J Cell Biol 1998, 140(5):1255-1263.

28. Wu LW, Mayo LD, Dunbar JD, Kessler KM, Baerwald MR, Jaffe EA, Wang D, Warren RS, Donner DB: Utilization of distinct signalling pathways by receptors for vascular endothelial cell growth factor and other mitogens in the induction of endothelial cell proliferation. J Biol Chem 2000, 275(7):5096-5103.

29. Lewis TS, Shapiro PS, Ahn NG: Signal transduction through MAP kinase cascades. Adv Cancer Res 1998, 74:49-139.

30. Thomas SM, Brugge JS: Cellular functions regulated by Src family kinases. Annu Rev Cell Dev Biol 1997, 13:513-609.

31. Kilarski WW, Jura N, Gerwins P: Inactivation of Src family kinases inhibits angiogenesis in vivo: implications for a mechanism involving organization of the actin cytoskeleton. Exp Cell Res 2003, 291(1):70-82.

32. Koh W, Sachidanandam K, Stratman AN, Sacharidou A, Mayo AM, Murphy EA, Cheresh DA, Davis GE: Formation of endothelial lumens requires a coordinated PKC\{epsilon\}-, Src-, Pak- and Raf-kinasedependent signalling cascade downstream of Cdc42 activation. J Cell Sci 2009, 122(11):1812-1822.

33. Guertin DA, Sabatini DM: Defining the role of mTOR in cancer. Cancer Cell 2007, 12(1):9-22

34. Lee DF, Hung MC: All roads lead to mTOR: integrating inflammation and tumor angiogenesis. Cell Cycle 2007, 6(24):3011-3014.

35. Drakos E, Rassidakis GZ, Medeiros LJ: Mammalian target of rapamycin (mTOR) pathway signalling in lymphomas. Expert Rev Mol Med 2008, 10: e4.

36. Wang D, Wang H, Brown J, Daikoku T, Ning W, Shi Q, Richmond A, Strieter R, Dey SK, DuBois RN: CXCL1 induced by prostaglandin E2 promotes angiogenesis in colorectal cancer. J Exp Med 2006, 203(4):941-951. 
37. Jabbour HN, Sales KJ: Prostaglandin receptor signalling and function in human endometrial pathology. Trends Endocrinol Metab 2004, 15(8):398-404.

38. Qian RZ, Yue F, Zhang GP, Hou LK, Wang XH, Jin HM: Roles of cyclooxygenase-2 in microvascular endothelial cell proliferation induced by basic fibroblast growth factor. Chin Med J (Engl) 2008, 121(24):2599-2603.

39. Finetti F, Solito R, Morbidelli L, Giachetti A, Ziche M, Donnini S: Prostaglandin E2 regulates angiogenesis via activation of fibroblast growth factor receptor-1. J Biol Chem 2008, 283(4):2139-2146.

40. Rao R, Redha R, Macias-Perez I, Su Y, Hao C, Zent R, Breyer MD, Pozzi A: Prostaglandin E2-EP4 receptor promotes endothelial cell migration via ERK activation and angiogenesis in vivo. J Biol Chem 2007, 282(23):16959-16968.

41. Tamura K, Sakurai T, Kogo H: Relationship between prostaglandin E2 and vascular endothelial growth factor (VEGF) in angiogenesis in human vascular endothelial cells. Vascul Pharmacol 2006, 44(6):411-416.

42. Taylor L, Foxall T, Auger K, Heinsohn C, Polgar P: Comparison of prostaglandin synthesis by endothelial cells from blood vessels originating in the rat, baboon, calf and human. Atherosclerosis 1987, 65(3):227-236

43. Sales KJ, Milne SA, Williams AR, Anderson RA, Jabbour HN: Expression, localization, and signalling of prostaglandin F2 alpha receptor in human endometrial adenocarcinoma: regulation of proliferation by activation of the epidermal growth factor receptor and mitogen-activated protein kinase signalling pathways. J Clin Endocrinol Metab 2004, 89(2):986-993.

44. Sales KJ, Battersby S, Williams AR, Anderson RA, Jabbour HN: Prostaglandin E2 mediates phosphorylation and down-regulation of the tuberous sclerosis-2 tumor suppressor (tuberin) in human endometrial adenocarcinoma cells via the Akt signalling pathway. J Clin Endocrinol Metab 2004, 89(12):6112-6118.

45. Sales KJ, Katz AA, Howard B, Soeters RP, Millar RP, Jabbour HN: Cyclooxygenase- 1 is up-regulated in cervical carcinomas: autocrine/ paracrine regulation of cyclooxygenase-2, prostaglandin e receptors, and angiogenic factors by cyclooxygenase-1. Cancer Res 2002, 62(2):424-432.

46. Battersby S, Sales KJ, Williams AR, Anderson RA, Gardner S, Jabbour HN Seminal plasma and prostaglandin E2 up-regulate fibroblast growth factor 2 expression in endometrial adenocarcinoma cells via E-series prostanoid-2 receptor-mediated transactivation of the epidermal growth factor receptor and extracellular signal-regulated kinase pathway. Hum Reprod 2007, 22(1):36-44

47. Ledingham MA, Denison FC, Kelly RW, Young A, Norman JE: Nitric oxide donors stimulate prostaglandin $\mathrm{F}$ (2alpha) and inhibit thromboxane $\mathrm{B}(2)$ production in the human cervix during the first trimester of pregnancy. Mol Hum Reprod 1999, 5(10):973-982.

48. Denison FC, Calder AA, Kelly RW: The action of prostaglandin E2 on the human cervix: stimulation of interleukin 8 and inhibition of secretory leukocyte protease inhibitor. Am J Obstet Gynecol 1999, 180(3 Pt 1):614-620.

doi:10.1186/1471-2121-11-8

Cite this article as: Keightley et al:: F-Prostaglandin receptor regulates endothelial cell function via fibroblast growth factor-2. BMC Cell Biology $201011: 8$ 